\title{
Investigation of Glacial Effects and the Permanent Snow Lines on the Southern Slopes of the Hamadan Alvand Kuh
}

\author{
Abdullah Seif ${ }^{1}$, Ali Bazvand ${ }^{2}$ \\ ${ }^{1}$ Natural Geography Department in the Faculty of Geography and Planning, University of Isfahan, Isfahan, Iran \\ ${ }^{2}$ Faculty of Geography and Planning, University of Isfahan, Isfahan, Iran \\ Email: alibazvand8@gmail.com
}

How to cite this paper: Seif, A. and Bazvand, A. (2018) Investigation of Glacial Effects and the Permanent Snow Lines on the Southern Slopes of the Hamadan Alvand Kuh. Journal of Geoscience and Environment Protection, 6, 120-142.

https://doi.org/10.4236/gep.2018.66010

Received: April 27, 2018

Accepted: June 25, 2018

Published: June 28, 2018

Copyright $\odot 2018$ by authors and Scientific Research Publishing Inc. This work is licensed under the Creative Commons Attribution International License (CC BY 4.0).

http://creativecommons.org/licenses/by/4.0/

(c) (i) Open Access

\begin{abstract}
One of the issues that geomorphology researchers have focused on is to trace the geomorphic effects and the snow lines in the Quaternary glaciers in Iran. This research has been carried out in the valleys of the southern slopes of Alvand Kuh Mountains, namely the Serkan and Mobarakabad valleys. The equilibrium line altitude between current and ancient glaciers is one of the parameters that is used as a variation indicator of climate. There are several ways to rebuild this parameter (Ancient ELA). Equilibrium Line altitude requires the accurate knowledge of glacial geomorphic landforms and evidence. According to Kuhle, Hofer and Luis methods, providing and estimating the ancient and permanent snow lines were carried out in this research during field operations within several intervals and the glacial geomorphic evidences were identified such as circuses, sidebar moraines and terminal moraines. The six glacier subwatersheds were developed in a study area based on Kuhle, Hofer and Luis methods in which only two valleys of Serkan 3 and Mubarak Abad 3 had a high degree of accuracy in their ELA drop rate and old snow lines. It should be noted that the current snowlines of the current study area are 4400 $\mathrm{m}$ and $1400 \mathrm{~m}$ (based on the Schweitzer map). The results of the estimated snow lines for each of the six valleys are shown in Table 4. At the present study, the main of the Mobarak Abad valley area was divided to six glacial valleys which are called Serkan 1, 2, 3 and Mobarak Abad 1, 2, 3 and then several layers were provided, including cirque layers, moraine layers, primary and secondary crest layers, high crest layers, 10-meter DEM layer, highlight, different contour line layers and valleys profiles and finally, the ultimate map of glacial geomorphology of Serkan and Mobarak Abad valleys was prepared.
\end{abstract}




\section{Keywords}

Serkan and Mobarak Abad Valleys of Alvand Kuh, Kuhle Method, Glacial Cirque, Quaternary Snow Line, Glacial Geomorphology Map

\section{Introduction}

According to the Pedrami glacial geomorphic maps (1982) [1] the altitude of the snow lines during the Wurm glaciation period at the height of 1600 meters from the Halgard icicle and in the north to the Kurdistan of Iraqi is located from Sardasht to Urumieh that is more than one region. He said that the glaciers and moraines were extended 400 meters to the down side in the Masuleh valley and in the west of Rasht, and he also believed that the moraines of the Wurm period are better observed in the Baneh.

According to the evidences (Ghahroudi and Hosni 2012) [2] there are three crests in the Qandil Mountains at the altitude of 3400 meters, that shows the snow lines in this region with the altitude of $1650 \mathrm{~m}$.

Seif \& Ebrahimi (2014) [3] studied and analyzed the morphometric and allometric parameters he glacial circuses in Bakhtiari Zard Kuh in a paper based on the Gis technique.

Bobck (1995) believes that in the glaciation period, the land of Iran had a cooler and dryer climate than the present climate (Ebrahimi, 2015).

Seif (2015) investigated completely about the glacial geomorphology and reconstructed the equilibrium line of the permanent and ancient glaciers of the Oshtoran Kuh. He used the Kuhle method in order to complete of the equilibrium line of the permanent glacier. In addition, he compared the results of Kuhle method with the TSAM, THAR and the circus floor height method. According to the values of the glacial equilibrium line ( $4500 \mathrm{~m}$ above sea level), the value of the drop of the Pleistocene equilibrium line in Oshtoran Kuh has been calculated $1420 \mathrm{~m}$. Based on the study of the glacier tongues, the maximum expansion of glaciers in this region had been between 2350 and $2400 \mathrm{~m}$ above the sea level. Due to the comparison of the calculated values for the drop of the glacial equilibrium line with the values recorded in other parts of the world, the maximum reconstructed glacial expansion has been matched to the maximum glacial expansion period. This study has shown that during the maximum glacial expansion, the average annual temperature drop was $9.94^{\circ} \mathrm{C}$ in Oshtoran Kuh.

Seif and Bagheri Sadr (2011) [4] have estimated the values of the permanent snow line about 2840-2920 meters above sea level in the Lorestan heights.

Seif and Rahdan (2012) [5] estimated the late permanent snow line from 2748 to 2842 meters and the snow line of the current age in the range between Dena to Zard Kuh from 1913 to 2127 meters above sea level.

Ghahroudi (2011) [6] in a study based on climatic heritages and morphological evidences, has estimated and compared the domains of permanent snow in 
the glacial period and the interglacial period of the Haraz basin in the central Alborz highlands. The results showed in the last cold period, the permanent territory of the snow has fallen to 1800 meters in the basin, and now this territory is about 3200 meters, indicating that more than 80 percent of the area of the basin has been under the glacial erosion during the cold periods.

Yamani (2006) [7] studied the geomorphologic evidences of glacial lines in the Zard Kuh slope. There are more than 15 circuses In the northwest slopes of these mountain slopes and around its main crests that are more than 4000 meters, and the expansion of the glacial circuses up to 2500 meters is limited to the Koohrang river bed, and the line of glacial circuses has at least 3400 meters height.

Wright (1962) [8] is one of the scholars who had a lot of studies on Iran. He believed that the climate was cold and dry in the Zagros region about 11,000 years ago, and the snow line expended toward the down until 800 meters in the Quaternary period.

Christophe Proy (1980) [9] in a study for Bakhtiari Zard Kuh heights confirmed the valley glaciers based on glacial geomorphic evidence in the northern slopes of Bakhtiari Zard Kuh, and in addition, he believes during the Wurm periods 1 , the length of these glaciers was 3 to 3.8 kilometers and its tongues drop up to the height of 3200 meters, as a result, the snow lines were located in the lower quaternary at lower altitudes, at the moment the height of the snow line is 4100 to 4200 meters.

Ghahroudi et al. (2013) [10] in the study of elevation in the Zagros Dinavar basin believes that the height of $2820 \mathrm{~m}$ was the boundary between two glacial and interglacial geomorphic systems.

The purpose of this study is to show the altitude of the snow lines in the last cold period of the year on the southern slopes of the Alvand mountain of Hamedan with a case study on the valleys of Sarkan and Mobarakabad and finally preparing a geomorphology map.

\section{Studied Area}

Serkan valleys and Mobarakabad Abad of Alvand Kuh Hamedan.

\subsection{Introducing the Studied Area}

\subsubsection{Hamedan Province Location}

Geographical location: Geographical coordinates of the Hamadan province are in degrees, minutes, seconds between the northern latitude of $34^{\circ} 0^{\prime} 0^{\prime \prime}$ to $35^{\circ} 0^{\prime} 0^{\prime \prime}$ and the eastern longitude of $48^{\circ} 0^{\prime} 0$ " to $49^{\circ} 0^{\prime} 0$ ". The area of this province is 19,355 square kilometers .(Figure 1)

Relative location: Hamedan province is one of the western provinces of Iran. This province from the north is limited to the provinces of Qazvin and Zanjan, and from the south until the Lorestan province, from the east to the central province and from the west to Kurdistan and Kermanshah provinces. Map of the province's location in Iran and in terms of geology and geomorphology struc- 
ture: Hamedan is one of the western provinces of Iran with morphological formations and special geological [11].

\subsubsection{Geographical Location of the Studied Areas}

Heights Alvand: Alvand mountainous mass with the direction of northwestsoutheast at the east longitude is located from $48^{\circ} 24^{\prime}$ to $48^{\circ} 32^{\prime}$ and at the north longitude from $34^{\circ} 32^{\prime}$ to $34^{\circ} 40^{\prime}$. This region is considered as the continuation of the Zagros Mountains and is located in the Urumieh Dokhtar border strip and its highest crest is "Gholeh" with the height of 3580 meters (Sahab Geography Institute, 1991) [12] (Figure 1).

This mountain is located in the northwest to the Sanandaj Khodabandehlu Kuh and the Kurdistan Chehelcheshmeh Kuh and from the southeast to Rasvand Mountains and Vafs Arak Mount. Its crest line is located between Hamedan and Tuyeserkan, and this mountain has several lush valleys, springs, meadows and crests.

Tuyeserkan is one of the highest mountainous regions of the western part of the country. The region can be imaged as a great gateway that is naturally located between the Alvand and Zagros mountains. This beautiful and spectacular area is naturally divided into three mountainous, mountainside and plains sections. What adds to the beauty of Tuyeserkan in terms of natural is its weather and greenery location of the mountainous regions, so that it is located along the path of the mountain range and the boundary between the mountainous and plain areas and it is the main pole of civilization in the region with having a favorable nature and a combination of the nature of mountainous and plain regions. The longitude of the city in terms of geog raphical coordinates is in degrees, minutes $34^{\circ} 20^{\prime}$ to $34^{\circ} 30^{\prime}$, and its attitude is $48^{\circ} 10^{\prime}$ to $48^{\circ} 30^{\prime}$, (Figure 1) and it is limited from the north to Hamedan and Assad Abad cities, and partly to Bahar city and from the east to Malayer city as well as from the west to Kangavar city and from the south to Nahavand city. The highest point of this city is Alvand
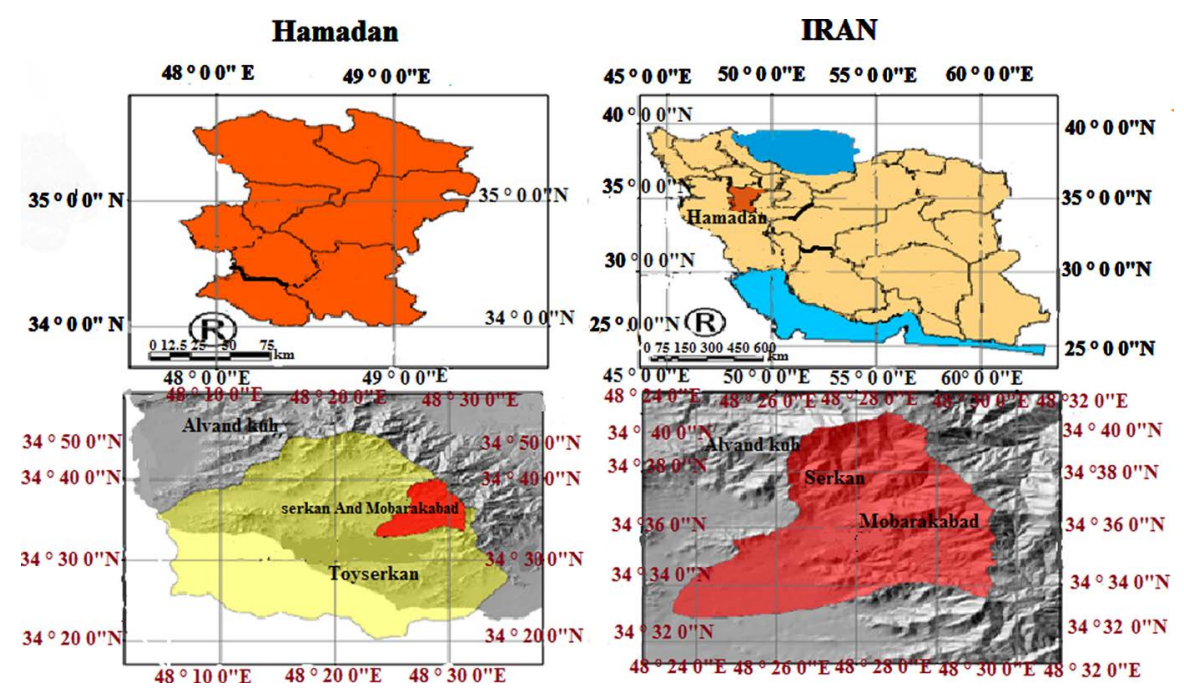

Figure 1. Location of the studid area, Source: Authors. 
crest with a height of 3574 meters, where is a common area of this city and the Hamedan city and its lowest point is the Karkhaneh village with a height of 1555 meters and its average height is 1784 meters above sea level.

The geographical coordinates of the Serkan city in east longitude are $48^{\circ} 30^{\prime}$ and $34^{\circ} 50^{\prime}$ (Figure 1)at the north latitude and its average height is 2040 meters above sea level as well as the area of the city is $2026 \mathrm{~km}^{2}$. Its shortest way is Chotash valley, Al-Muqalagh Valley, Vardavard Olya Valley and Gashin valley.

The "Serkan valley" lies in the southern crests of the Yakhchal Mountain and extends from north to south. The valley has full sunlight throughout the day due to its particular position. The valley firstly begins with the Artiman region, and then the "Serkan" is located.

Tuyeserkan is suffering from the water scarcity. Some important factors of water scarcity in the city include the existence of a high slope of the earth, a slight thickness of the deposits layers of the soil, small amount of precipitation, and the lack of control of surface waters. The water of the city comes from springs, Kanats and melting mountain' snow in hot seasons. This city has a temperate mountain climate due to its mountains and high altitude and its major rivers are Ghelghelrood, Karsanrood, Serkanrood and Sarabirood that their excess of water pours into the Gamasiab River after irrigation of agricultural land.

\section{Methods and Materials}

In order to research in the software environment, the digital databases and layers in need of the information have been prepared in the studied area to estimate the permanent snow line and to provide the glacial geomorphological maps.

\subsection{Research Methodology}

The research methodology consists of four titles, analytical methodology, research methodology, research tools of the survey and performing stages of the research.

\subsubsection{Analytical Methodology}

The current survey is a scientific research, because this research involves with objective and measurable data and phenomena in most cases and evaluates the phenomenon accurately. In the study, the descriptive and empirical approaches are used in the path of identifying processes and glacier forms, understanding the relationship between factors and phenomena as well as accessing a comprehensive combination attitude. In this research, the type of study and the method of examining hypotheses is a combination of descriptive and empirical attitudes. Initial identification and analysis of effective phenomena were investigated in the framework of empirical attitude for the formation of landforms and glacier effects in the framework of the descriptive attitude, measurements and calculations related to glacial forms, the relief features of the earth against the forma- 
tion processes, analysis of the degree of evolution of specific landforms, morphometric analysis and estimation of the ancient snow line.

\subsubsection{Research Methodology}

The research methodology includes documentary and library reviews, field observations, data extraction, modeling and comparison of results.

Basic and general information on the subject, theoretical fields of research, research literatures, and other relevant studies conducted by researchers, as well as data and information from organizations such as meteorology, geology and the mapping organization, are obtained as the foundation of the study through the library-documentary studies and searches on the Internet.

A major part of the information and data required for research were obtained through the direct reference to the environment, field study and the laboratory operations. Other sections of the information are obtained through indirect observations and the study of topographic maps, altitude digital models, geological maps and satellite imagery and their comparison of information through relevant software.

Another part of the research is to examine the data obtained from different sources as well as comparing and matching the results. In this section, the information obtained from the previous steps as well as laboratory data are compared and matched with the help of various software which are based on the basic maps.

Using the relationships and formulas and modeling and evaluating the results of models with real data and analyzing the results of modeling and comparing the results with other similar studies in the international level, is another part of the methodology of this research.

\subsubsection{Research Tools}

Research tools are divided into two groups of physical instruments and conceptual tools as follows:

Physical tools: These tools are used as follows
a1) Topographic Maps
a2) Geological Maps
a3) Satellite Images
a4) Digital attitude Data
a5) Meteorological Data
a6) Computer Software, The software used in this research include:

- Software related to GIS and remote measurement, including the Arc GIS software, version 10, Google Earth software, this software is considered as the most important tool for analyzing, storing and managing the spatial data.

- Editing and graphic software includes the Office 2015 and Photoshop.

a7) The camera for recording events and phenomena, GPS to record the location of phenomena and computers are other important physical instruments in this research. 
b) Conceptual tools: This tool mainly includes:

b1) Mathematics equations, formulas, empirical models are considered as the most important conceptual tools of research. Using these equations, data and quantities have been categorized and analyzed.

b2) The theoretical foundations and principles of geomorphology as the inevitable foundations for matching findings, especially theories of previous scholars are the basis for the activities of this research.

\subsubsection{The Stages of Performing the Research}

After the initial studies, the gathering of information and the explanation of theoretical foundations, according to the methods, tools, variables, research tools and methods of data analysis, the stages of performing research are done as follows. It is necessary to note that in this section, the general stages of performing research and the details of the research method are presented according to the purpose and hypotheses of the research and based on the summary of the basic foundations of the research.

1) The stage of identification and determination of the current status: the current status was recognized through the investigation of relevant research documents, field operations, and especially satellite images, 3D modeling, topographic maps, geology, and altitude digital models. This information is managed in the Geographic Research Database of the research was controlled to provide the final recognition of the morphological forms in later sections.

2) Identification stage and separation of the landforms: Based on the information obtained from the first stage and according to the apparent and morphometric specifications of the glacial landforms and related modeling, landforms were identified and differentiated, and after the final ground controls, glacial geomorphologic maps of the studied areas are mapped.

3) Analysis and calculation stage: At this stage, the meteorological information, the results of the stages $\mathrm{A}$ and $\mathrm{B}$, and the methods of reconstruction of the ancient climate were used and the results were interpreted using statistical methods in the preparation of diagrams and data analysis.

4) The assessment and interpretation stage of the results: Based on the results of the previous steps, the spatial arrangement of glacial forms and their quality are investigates and compared and the final results are interpreted based on the hypothesis of the research.

\subsection{Geographic Database of the Studied Areas}

The most important data used in the research are as follows:

Topographic maps have been used as the base maps for recording the field data and the description of the location of glacial phenomena. Topographic maps in this research are in the form of file format layout with a scale of 1:50,000 and locations of Nahavand, Kian, Firoozabad, and Phoshaj with a map number of 5658. The locations of Malayer, Dawijan, Ashtinan, Hossein Abad Shamloo, 
with the Map Sheet number 5758, prepared by the National Mapping Organization, are used. The characteristics of the maps used are presented in Table one.

Geological maps have been used as the basis maps for the study of lithology and the dominant structures in the studied areas and the study of the structural landforms. The maps used in this study were prepared by Tuyserkan, Malayer, Nahavand at 1:100,000 scale by Geological Survey of Iran.The specifications of the maps used in this study are presented in Table 1.

Satellite images obtained from the Google Earth software have been used to study the glacial forms' locations and indirect observation of these geomorphological features s, the construction of 3D models, as well as the recognition of other glacial features.

Digital Elevation Model (DEM) [13] is another important tool in this research. In this research, a digital model prepared by the National Mapping Organization has been used by the resolution of 10 meters (Table 1 ).

One of the most important data used in this research is the data from the meteorological stations (climatological and synoptic stations), especially temperature and precipitation data in the studied area.

\section{Research Findings}

\subsection{Glacial Geomorphology Map of Sarkan and Mobarakabad Valleys}

Since the exact reconstruction of the ancient equilibrium line altitude depends on the exact recognition of the geomorphologic glacial evidences, the location of the ancient glacial various evidences has been recognized on the basis of the satellite data and controlled during field visits. The results of these studies have finally been presented in glacial geomorphologic maps by study of subwatersheds.

Identification and various ancient glacial evidence such as sidebar moraines

Table 1. List of all types of maps and digital data used in this research.

\begin{tabular}{cccc}
\hline Type of map & Location & Scale & Statistical data (Map sheet number) \\
\hline Topography & Nahavand & $1: 50,000$ & 5658 \\
Topography & Kian & $1: 50,000$ & 5658 \\
Topography & Firozabad Bala & $1: 50,000$ & 5658 \\
Topography & Fasfaj & $1: 50,000$ & 5658 \\
Topography & Malayer & $1: 50,000$ & 5758 \\
Topography & Davijan & $1: 50,000$ & 5758 \\
Topography & Oshtorinan & $1: 50,000$ & 5758 \\
Topography & Hosainabad Shamlu & $1: 50,000$ & 5758 \\
Geology & Tuyeserkan & $1: 100,000$ & - \\
Geology & Nahavand & $1: 100,000$ & - \\
Geology & Malayer & $1: 100,000$ & - \\
Digital Elevation Model & Alvand & - & DEM 10 meters
\end{tabular}


and terminal moraines and glacier circuses were identified based on satellite imagery and monitored during field visits. The results of these field operations and surveys in glacial geomorphology maps have been presented. In this study, the studied area was divided into six glacier valleys.

In order to prepare a glacial geomorphology, the glacial circuses were traced through the images on Google earth and field operations. 10 m DEM for Eight circuses were identified. Three circuses were recognized in the glacial subwatersheds of the Mobarakabad, as well as in three the three subwatersheds of the Serkan 1, 2 and 3, five glacial circuses were traced and recognized. In this study, two subwatersheds were selected and recognized among the sextet separated subwatersheds surrounding the Alvand Mountain for further studies that are the most obvious glacial landforms. In the final map of geomorphology (Figure 2) we have determined the highest and lowest sub-basins of the Sarkan and Mubarakadabad basins, respectively, by establishing the Astraller ranking plan, which is as follows:

1) The highest altitude is 1 (3228) $\mathrm{m}$ and its lowest elevation is $2584 \mathrm{~m}$.

2) The highest altitude is 2 (3561) $\mathrm{m}$ and its lowest elevation is $2396 \mathrm{~m}$.

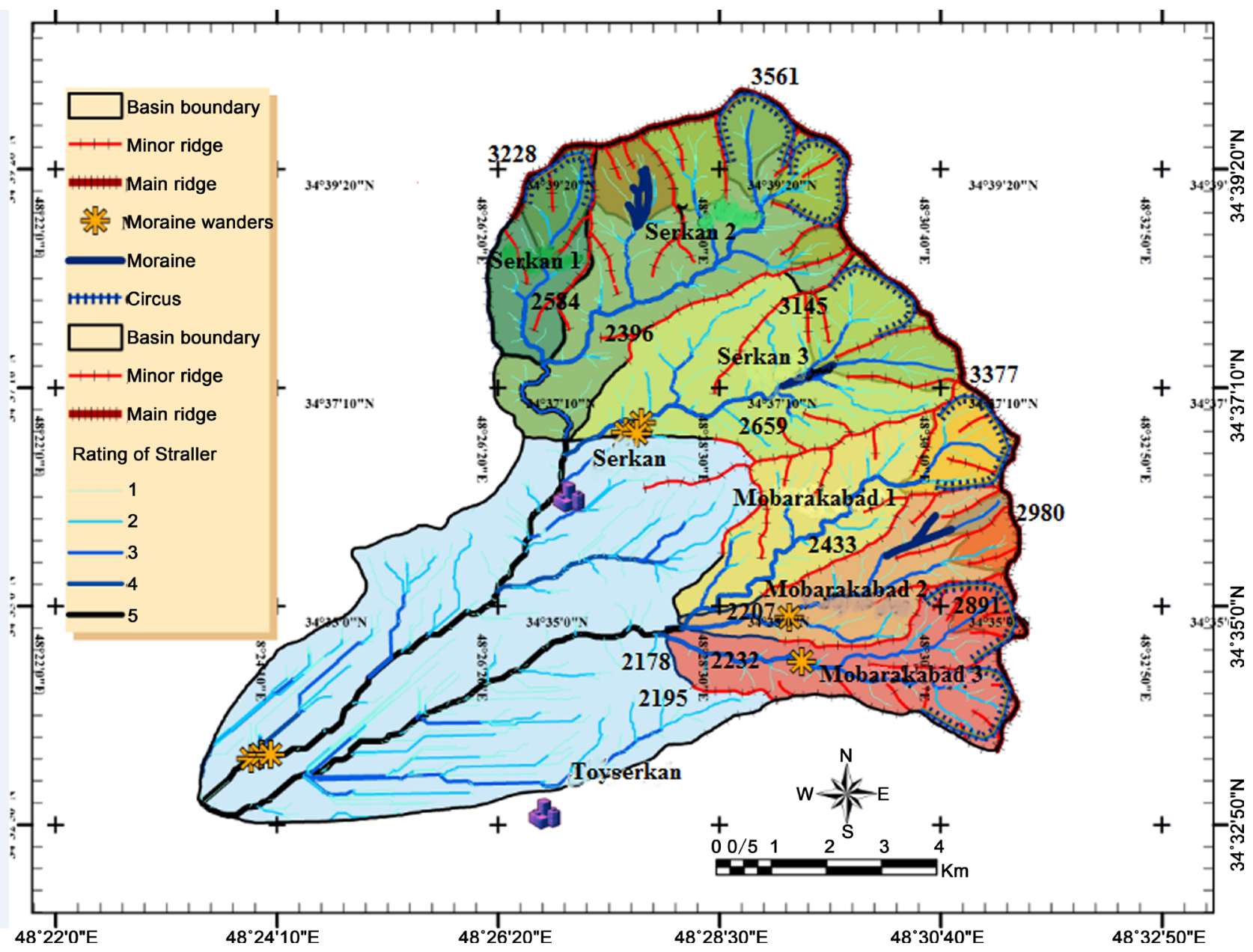

Figure 2. Final geomorphology map with reference to geomorphic layers. 
3) The highest altitude is 3 (3145) meters and its lowest elevation is 2659 meters.

4) The highest altitude of Mobarakabat 1 (3377) $\mathrm{m}$ and its lowest elevation (2433) meters.

5) The highest altitude of Mobarak Abad 2 (2980) meters and its lowest elevation (2207) meters.

6) The highest elevation of Mobarak Abad 3 (2891) meters and its lowest elevation (2232) meters.

At this stage we combined all glacial geomorphological features and evidences as a layer (the layer of the circuses, sidebar moraines, erratic rocks, and pseudo-circuses) with other GIS layers such as contour lines, glacial subwatershed layers, topography divide and layer of altitude crests (Figure 3 and Figure 4) and we could provide the final glacial geomorphologic of the Serkan valley map. (Figure 5)

At this stage we combined all glacial geomorphological features and evidences as a layer (the layer of the circuses, sidebar moraines, erratic rocks, and pseudo-circuses) with other GIS layers such as contour lines, glacial subwatershed layers, topography divide and layer of altitude crests (Figure 6 and Figure 7) and we could provide the final glacial geomorphologic of the Mobarakabad valley map. (Figure 8)

\subsection{Calculation of Permanent Snowlines and Assessment of the Loss Rate of the Equilibrium Line of the Sextet Glacial Valleys of the Serkan and Mobarakabad with Kuhle, Hoffer, and Luis Method (Based on Tables 2-4)}

1) Serkan terminal: If we assume that the erratic rocks have the glacial origin,
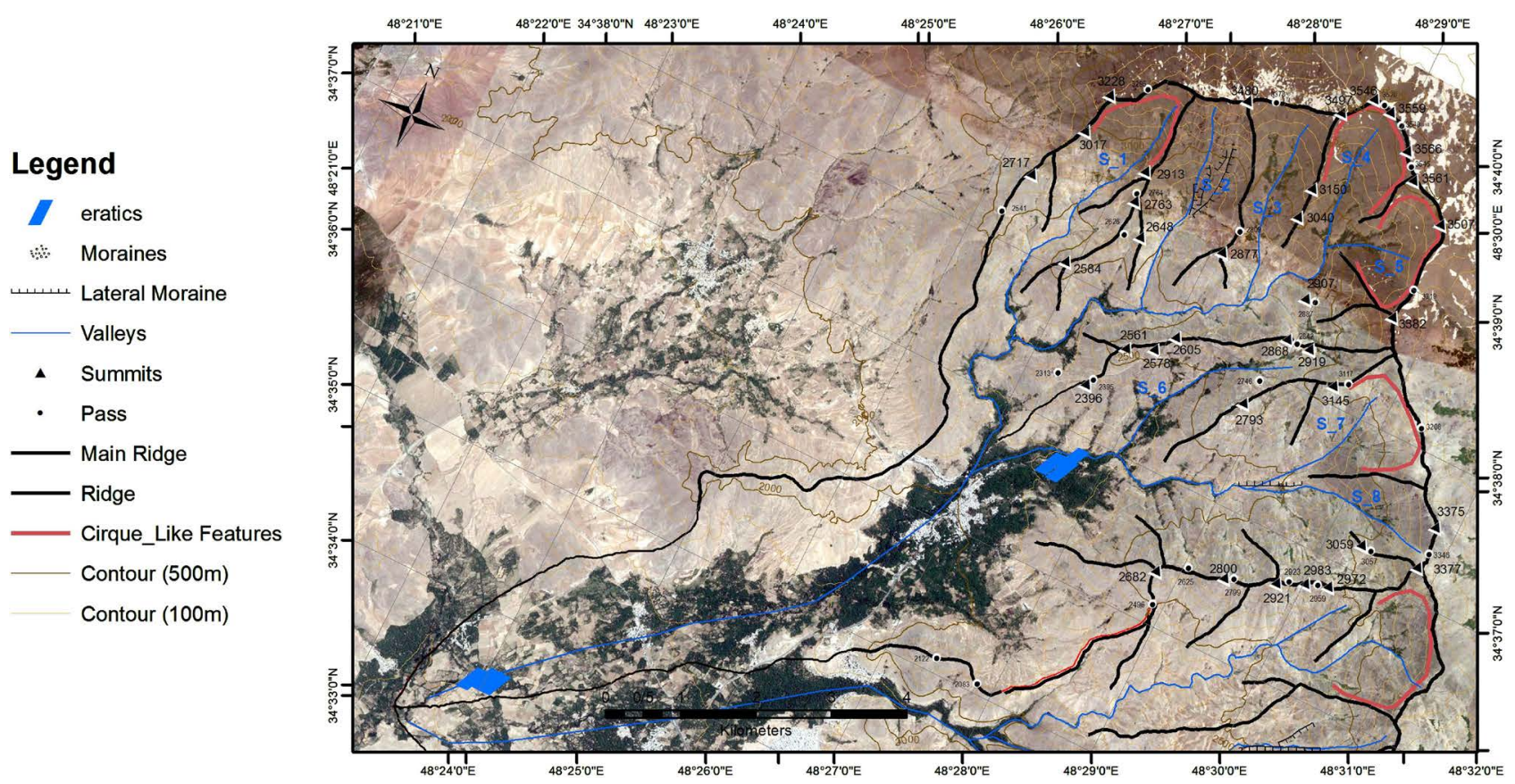

Figure 3. Glacial geomorphological features map of the Serkan valley on the pictures of Google earth. 


\section{Legend}

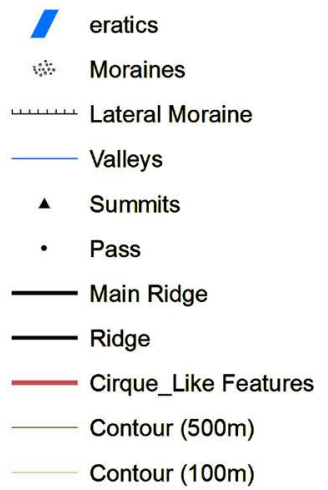

\section{Legend}

Contour $(100 \mathrm{~m})$
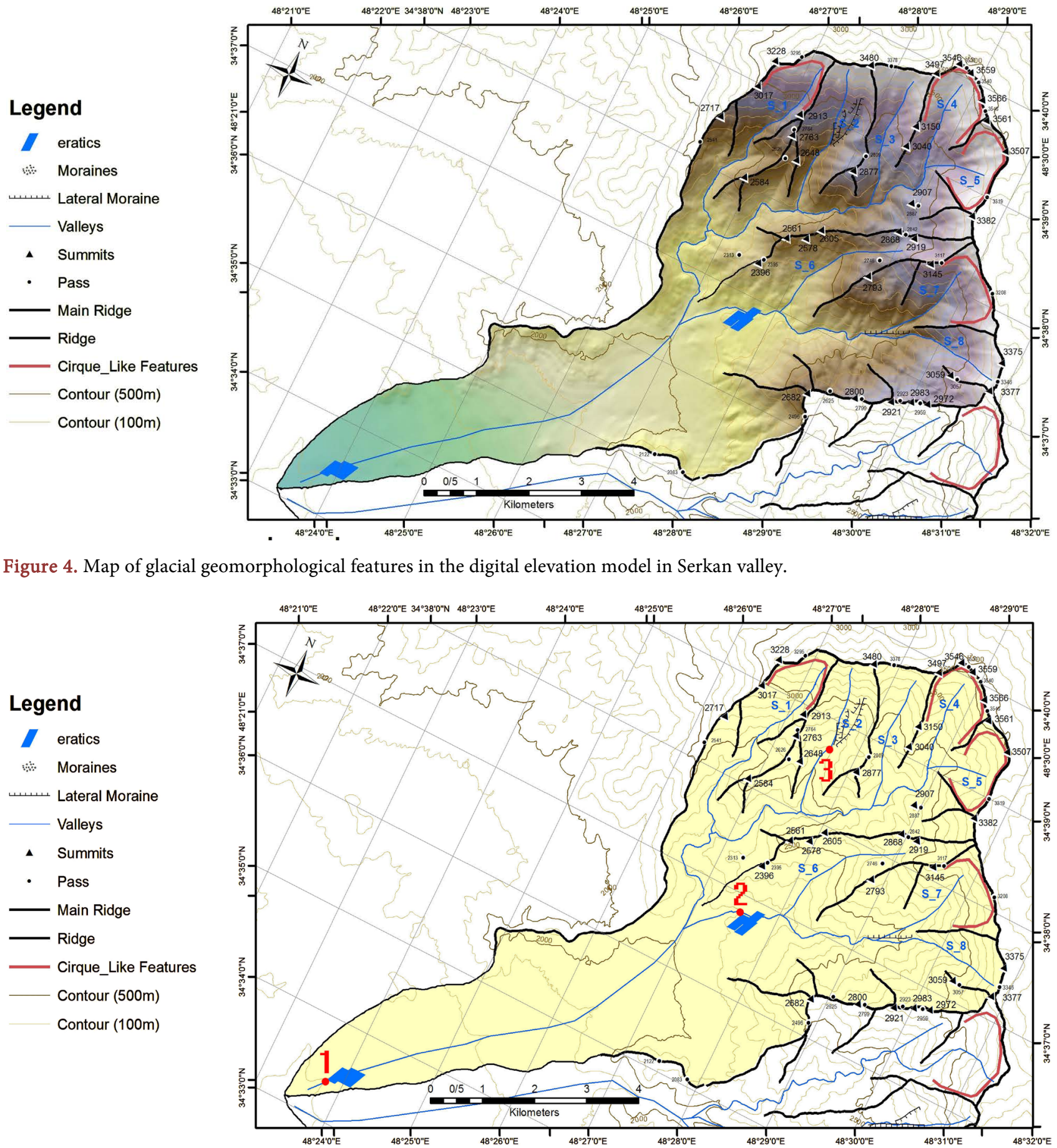

Figure 4. Map of glacial geomorphological features in the digital elevation model in Serkan valley.

Figure 5. Glacial geomorphological map of Serkan valley prepared in the ARC GIS environment.

then calculating through of the Kuhle method [14] (2298 m), Hoffer method (2462 $\mathrm{m}$ ) and Luis method (2643 m), according to current age ELA (4400) that has been extracted from the doctoral dissertation (Ebrahimi, Babak 2014), therefore the loss rate will be ELA $\Delta=2102$, and if the current age ELA is equal $4100 \mathrm{~m}$ (Schweitzer, 1972), as a result, the ELA loss rate will be ELA $\Delta=1802$. Given such this loss has not been presented in any reference, it can be concluded 

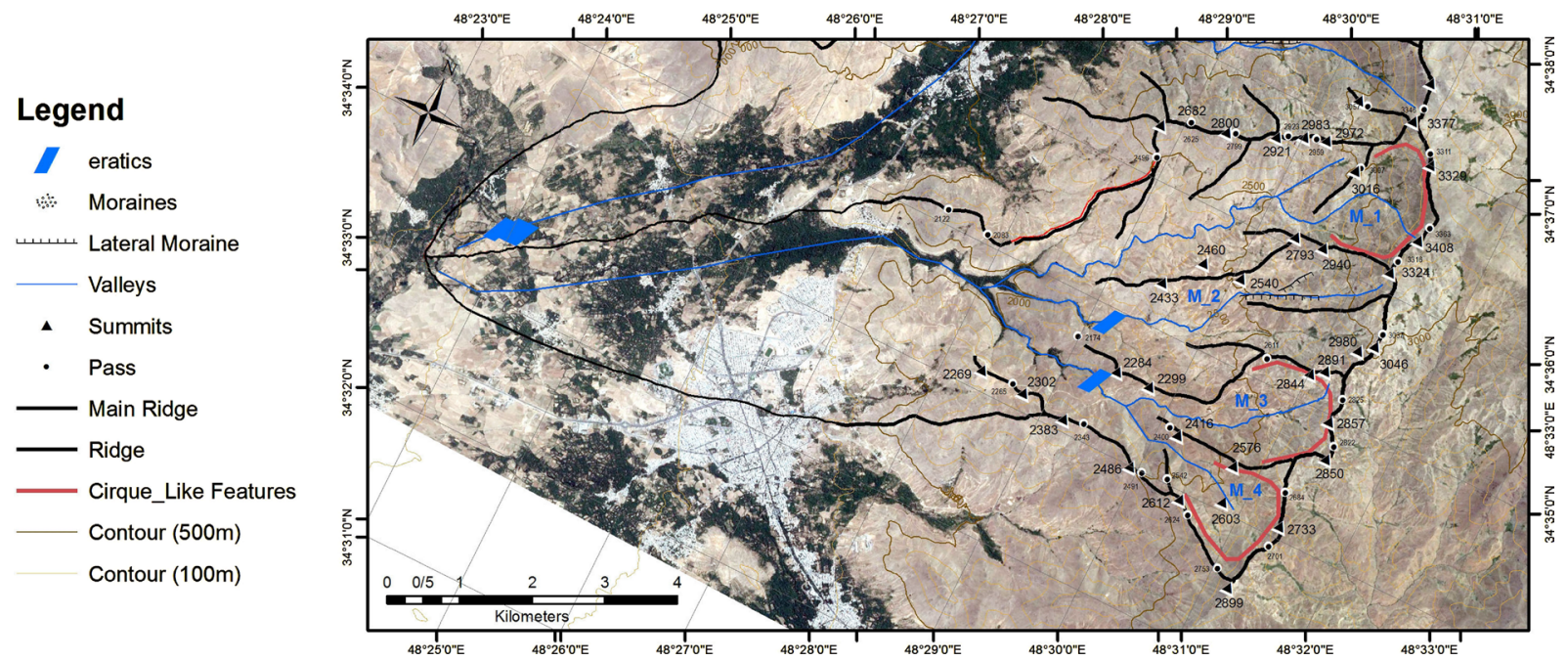

Figure 6. Glacial geomorphological features map of the Mobarakabad valley on the pictures Of Google earth.
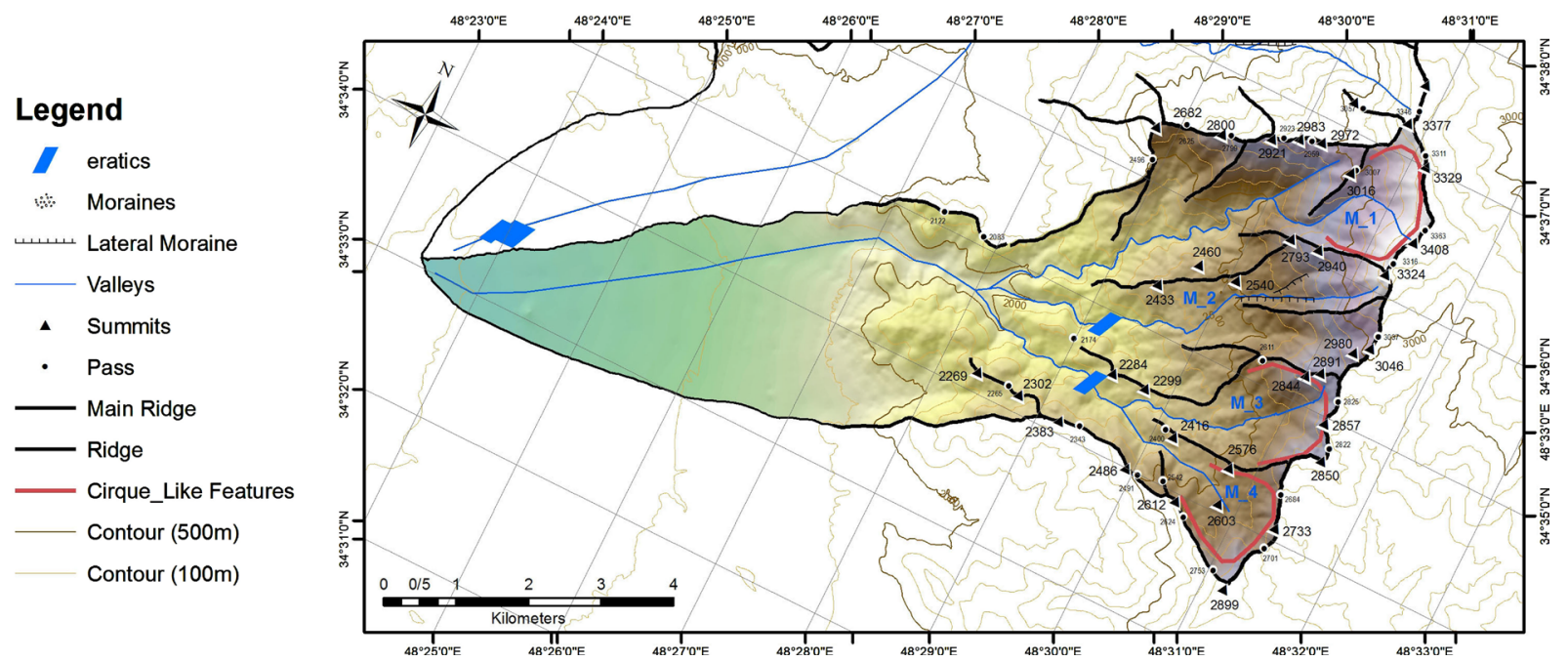

Figure 7. Map of glacial geomorphological features in the digital elevation model at Mobarakabad valley.
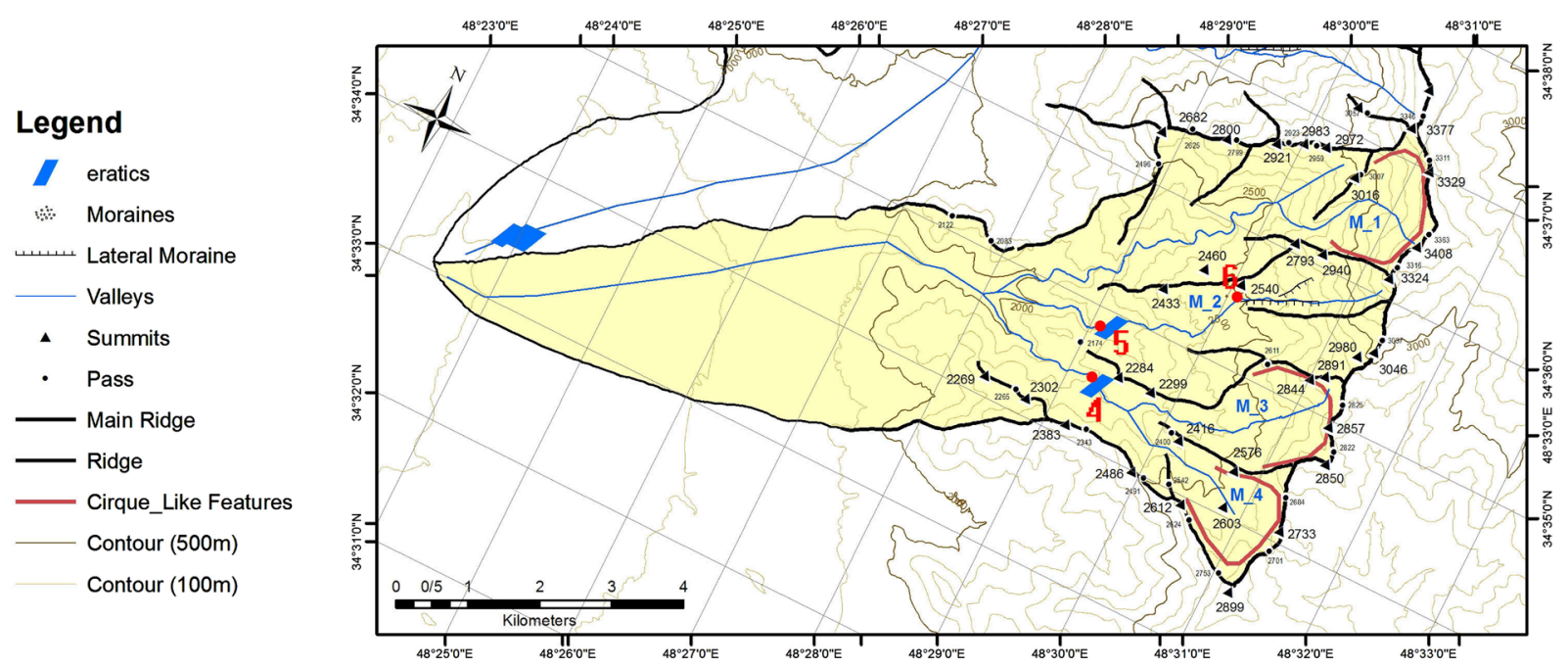

Figure 8. Glacial geomorphological map of Mobarakabad valley prepared in the ARC GIS environment. 
Table 2. Calculation of the values for attitude lines of the equilibrium line in all glacial terminals of the subwatersheds for the Sarkan valley.

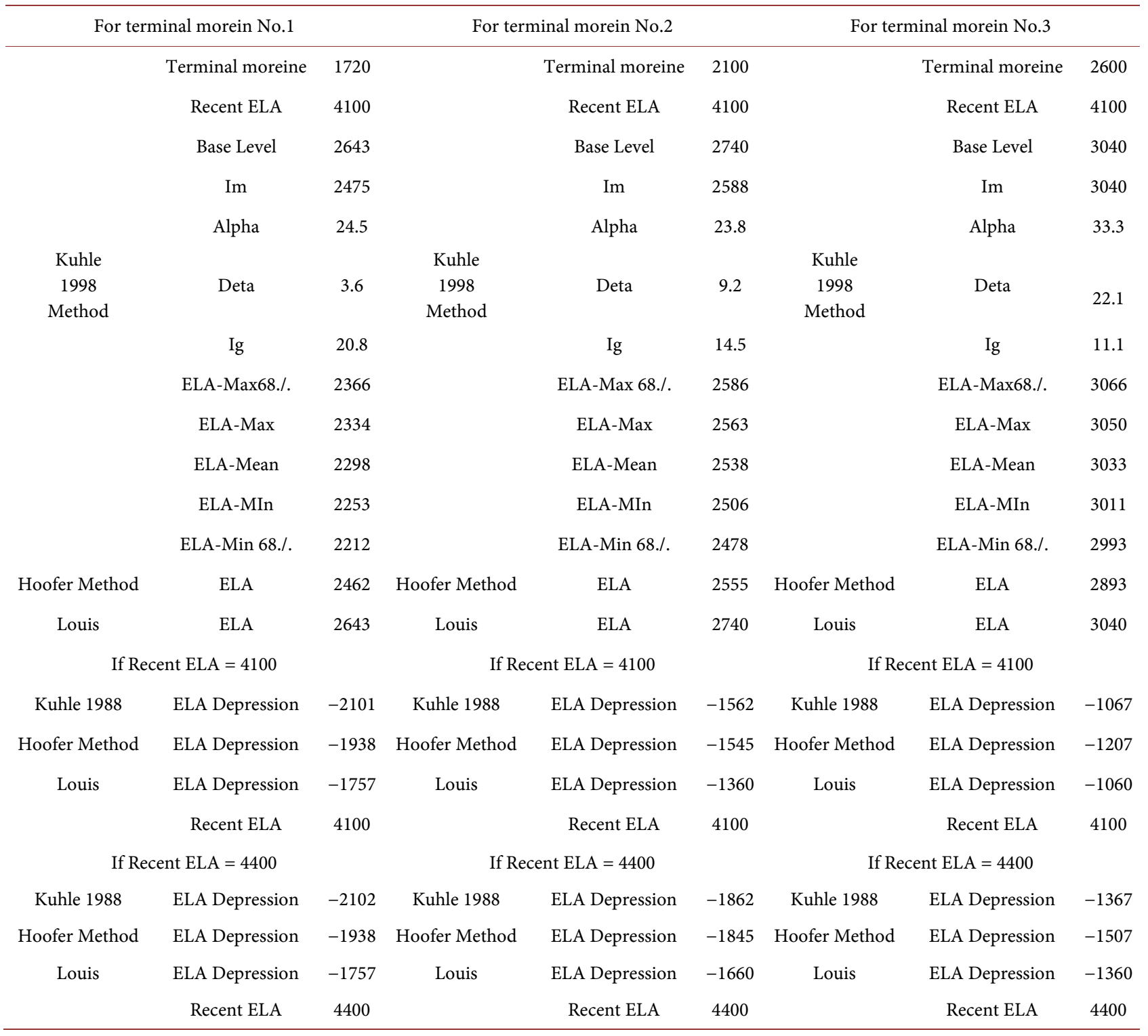

the observed erratic rocks have the non-glacial origin, and the ELA in this area must be much higher than the 2298 meters.

2) Serkan terminal: If we assume that the erratic rocks have the glacial origin, then calculating through of the Kuhle method $(2538 \mathrm{~m})$, Hoffer method (2555 $\mathrm{m})$ and Luis method $(2740 \mathrm{~m})$, according to current age ELA (4400) that has been extracted from the doctoral dissertation (Ebrahimi, Babak 2014), therefore the loss rate will be ELA $\Delta=2100$, and if the current age ELA is equal $4100 \mathrm{~m}$ (Schweitzer, 1972), as a result, the ELA loss rate will be ELA $\Delta=1562$. Given such this loss has not been presented in any reference, it can be concluded the observed erratic rocks have the non-glacial origin, and the ELA in this area must be much higher than the 2538 meters. 
Table 3. Calculation of the values for attitude lines of the equilibrium line in all glacial terminals of the subwatersheds for the Mobarakabad valley.

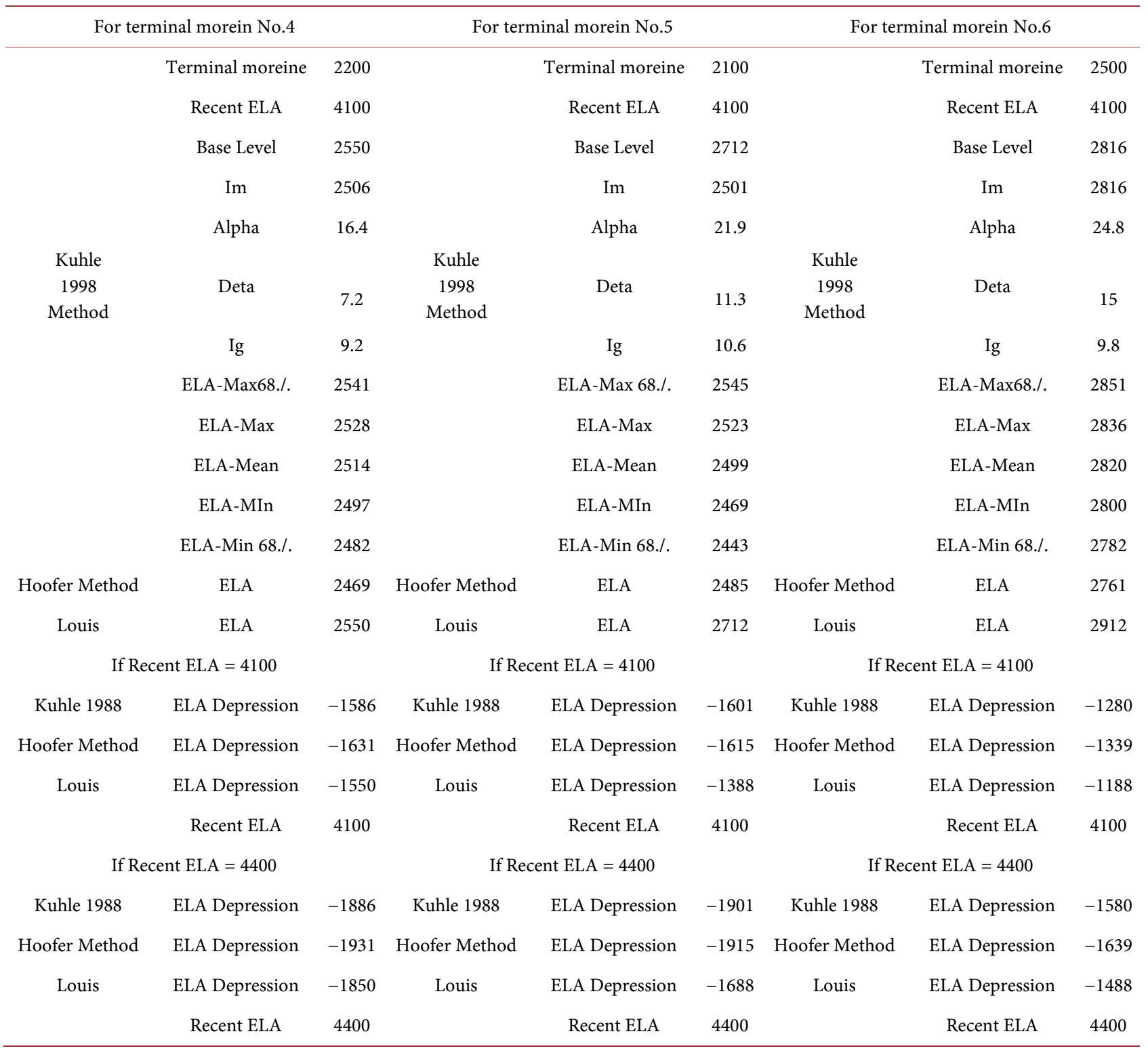

Table 4. Calculating ELA and ELA $\Delta$ with Kuhle, Hoffer, and Luis methods.

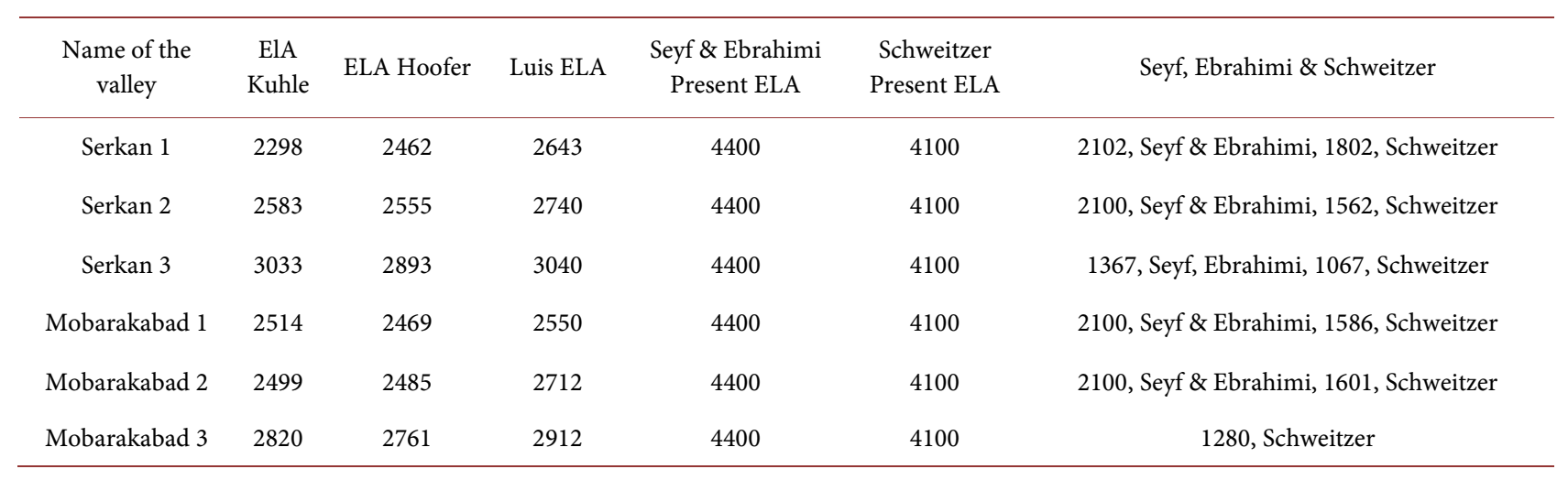


3) Serkan terminal: Calculation ELA through of the Kuhle method is (3033 $\mathrm{m})$, and it will be $(2893 \mathrm{~m})$ by Hofer method and is equal (3040 m) by Luis method, therefore we conclude that ELA = 3033 with 1367 and ELA $\Delta=1067$ and according the ELA loss matching with the global values of Wurm ELA loss, it can be concluded that the Serkan terminal 3 has the glacial resource, and therefore the average Wurm ELA in this area is accepted by the Kuhle, Hoffer and Luis methods.

4) Mobarakabad terminal: If we assume that the erratic rocks have the glacial origin, then calculating through of the Kuhle method $(2514 \mathrm{~m})$, Hoffer method (2469 $\mathrm{m}$ ) and Luis method (2550 m), according to current age ELA (4400) that has been extracted from the doctoral dissertation (Ebrahimi, Babak 2014), therefore the loss rate will be ELA $\Delta=2100$, and if the current age ELA is equal $4100 \mathrm{~m}$ (Schweitzer, 1972), as a result, the ELA loss rate will be ELA $\Delta=1586$. Given such this loss has not been presented in any reference, it can be concluded the observed erratic rocks have the non-glacial origin, and the ELA in this area must be much higher than the 2514 meters.

5) Mobarakabad terminal: If we assume that the erratic rocks have the glacial origin, then calculating through of the Kuhle method (2499 m), Hoffer method (2485 $\mathrm{m}$ ) and Luis method (2712 m), according to current age ELA (4400) that has been extracted from the doctoral dissertation (Ebrahimi, Babak 2014), therefore the loss rate will be ELA $\Delta=2100$, and if the current age ELA is equal $4100 \mathrm{~m}$ (Schweitzer, 1972), as a result, the ELA loss rate will be ELA $\Delta=1601$. Given such this loss has not been presented in any reference, it can be concluded the observed erratic rocks have the non-glacial origin, and the ELA in this area must be much higher than the 2499 meters.

6) Mobarakabad terminal: ELA Calculation by Kuhle is $(2820 \mathrm{~m})$, the Hoover $(2761 \mathrm{~m})$ and method by Luis method are equal $(2912 \mathrm{~m})$, and comparing the ELA calculation based on Kuhle method with ELA loss (1280) can be slightly related to the Wurm glacial period, so this ELA is accepted from 2800 to $2900 \mathrm{~m}$.

It is noteworthy that All Calculations, formulas and the Kuhle, Hoffer and Luis method have been explained in detail in Ebrahimi (2015) And Saif (2015) References. Please refer to these references for more information about these methods, (Ebrahimi, Babak, 2014, the end of the dissertation) [15]. So, here, only the results of these calculations are briefly summarized in Tables 2-4 as follows.

\subsection{Images of Field Operations in the Studied Area of the Serkan and Mobarakabad Valleys}

During field operations, along with the supervisor of the geomorphology team, a number of glacial geomorphologic evidences were traced and visited, including the sidebar moraines, terminal moraines, erratic rocks and thick sediments located at the last plain in the studied area.

Which took pictures of the circuses of the valleys of the Sarakan (Figure 9) and the morinas located at the bottom of the Sarakan valley in the upper part 
(Figure 10), as well as the lateral moraines of the valleys of the valleys (Figure 11) and the morinas of the regions surrounding the valleys adjoining the valley (Figure 12), In which the frozen glacier moraines were destroyed due to physical weathering (Figure 13), as well as glacial false morinas in the village of Mubarakabad (Figure 14)

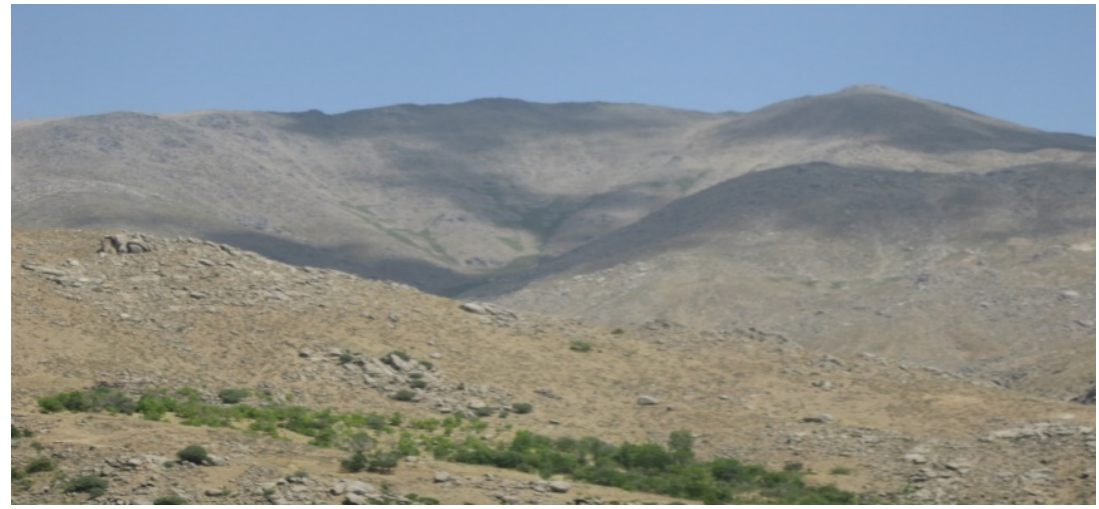

Figure 9. One of the glacial circuses of the Serkan valley in Alvand Kuh of Hamedan (Image by the authors: Seyf and Bazvand).

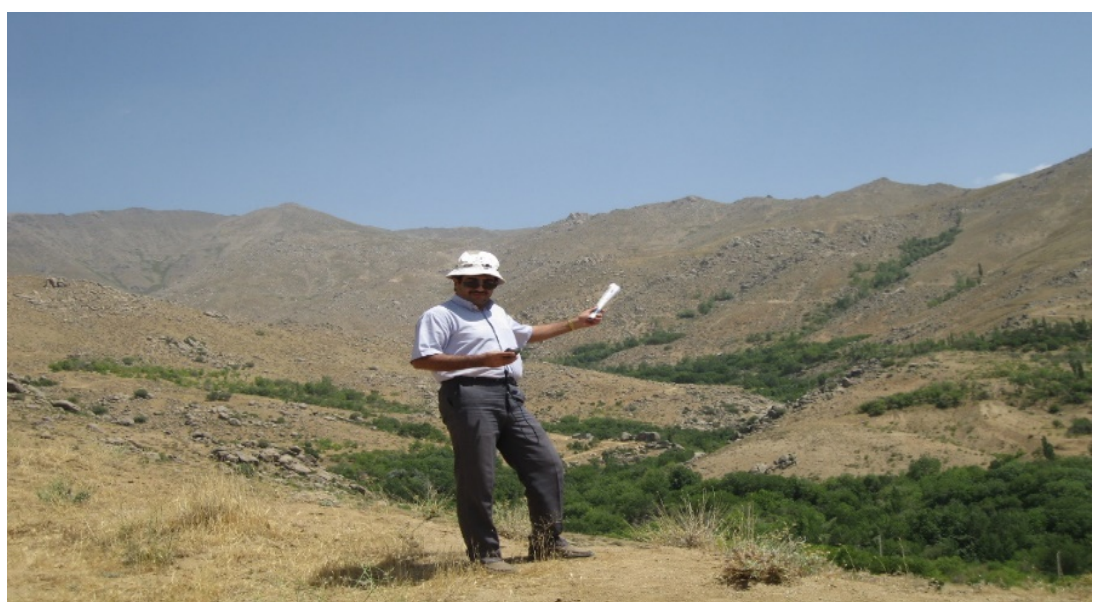

Figure 10. Dr. Seif indicates to the moraines located in the bottom of the Sarkan valley in the upper part.

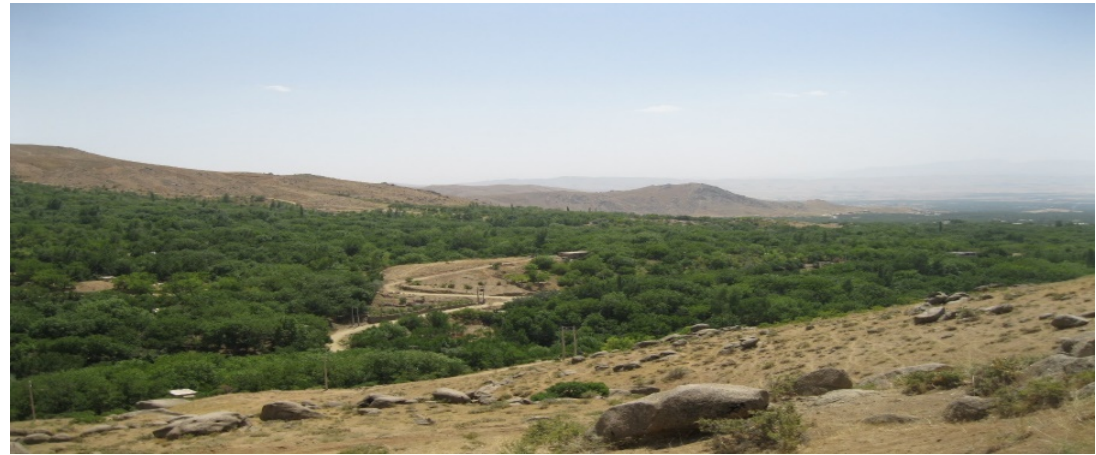

Figure 11. The image shows the sidebar moraines of the Serkan valley (image by the authors: Seif and Bazvand). 


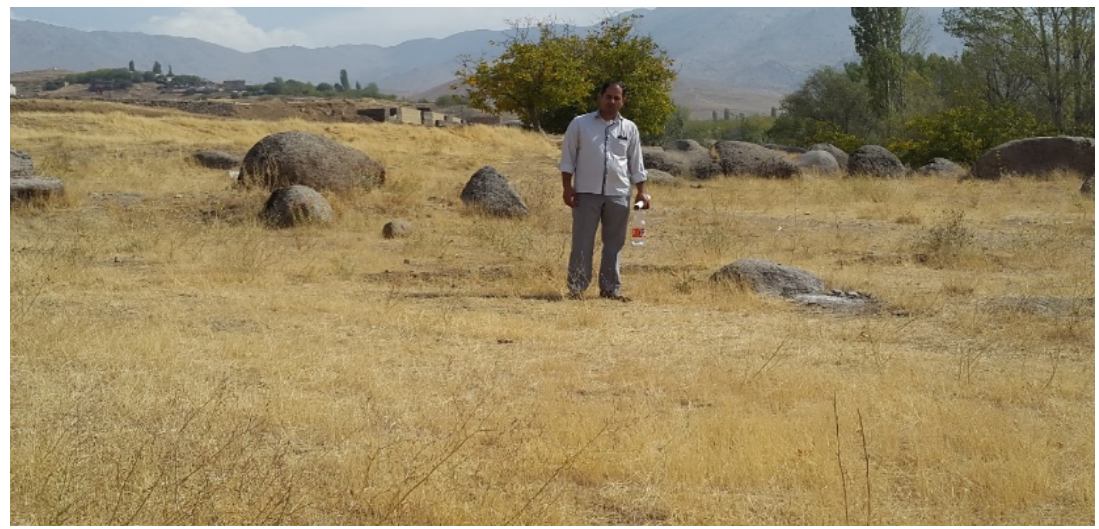

Figure 12. Glacier moraines around the valleys near the Sarkan (Bazvand).

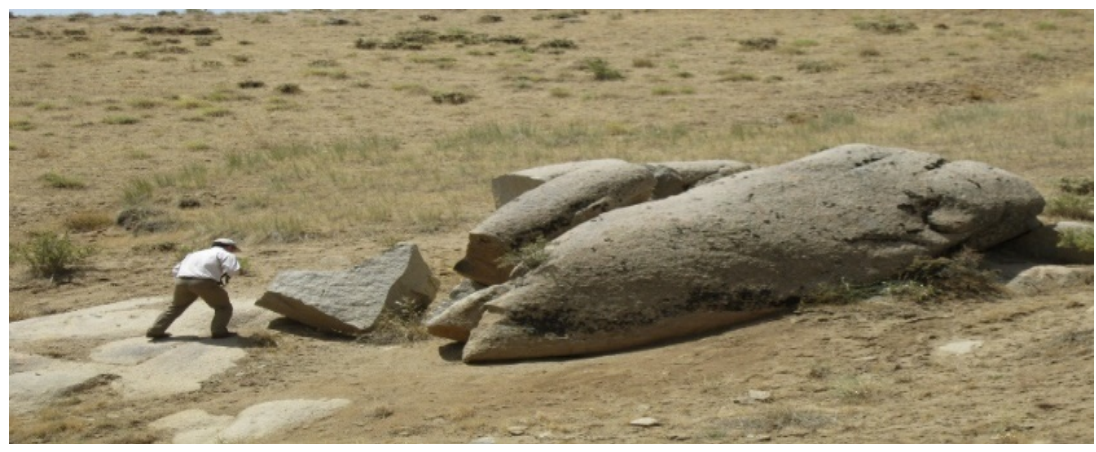

Figure 13. Scattered glacial moraines arising from physical weathering (Image by Seif and Ebrahimi).

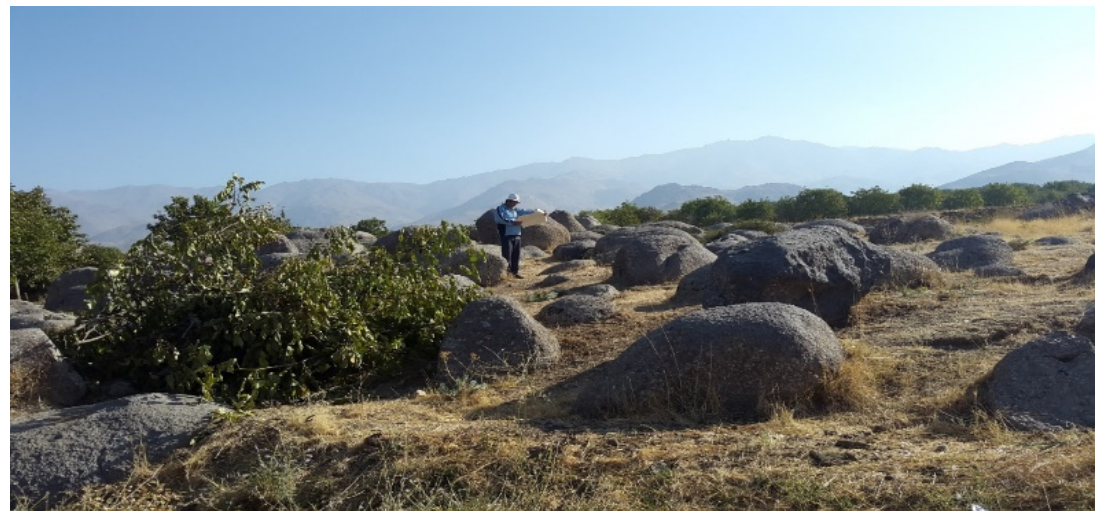

Figure 14. Glacial false moraines in the Mobarakabad village (Image by the authors: Seif and Bazvand).

\subsection{Profile of Main Valleys and Sub-Valleys (Glacial Valleys Study)}

To provide the elevation profiles of the 6 glacial valleys in the ArC GIS software environment with GIS operations on 10 meters DEM, it was provided the profiles on the main thalweg of each of the six valley (Figure 15) sand transferred to the EXCEL software environment after plotting their unprepared profile and in that environment, some operations were carried out, such as elevation in the $\mathrm{Y}$ column, and in the $\mathrm{X}$ column, the length of the valley was named by meters. And 
finally, the profile of all the valleys of Serkan and Mobarakabad (6 valleys) was plotted by the name of the valleys of Serkan 1,2 and 3, and the valleys of Mobarakabad 1, 2 and 3 (Figure 16).

\subsection{Results}

During field operations, along with the supervisor of the geomorphology team, a number of glacial geomorphologic evidences were traced and visited, including the sidebar moraines, terminal moraines, erratic rocks and thick sediments

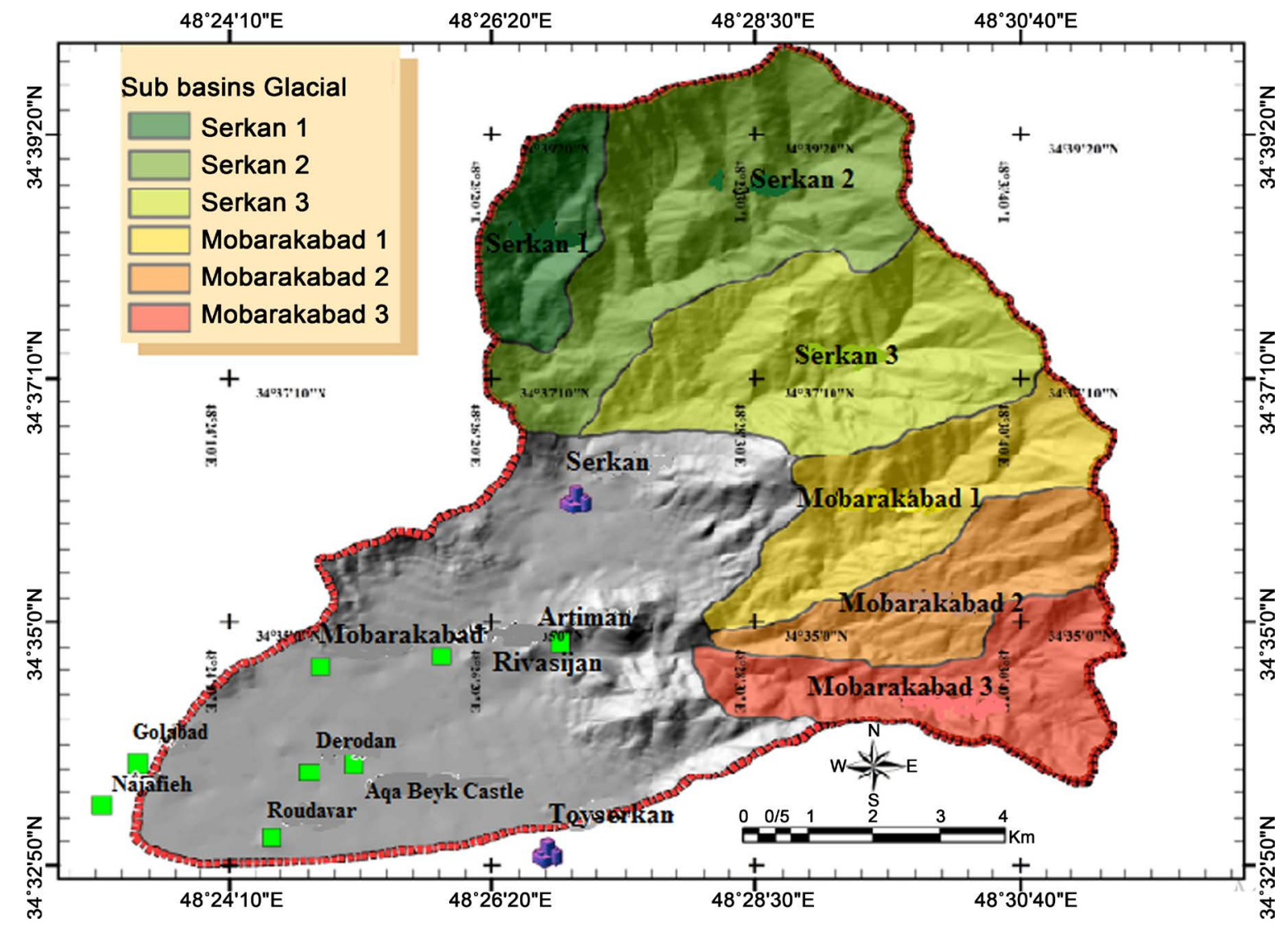

Figure 15. Combining map layers of glacial watersheds, Conduits on the shadow layer (profile of main and sub valleys).

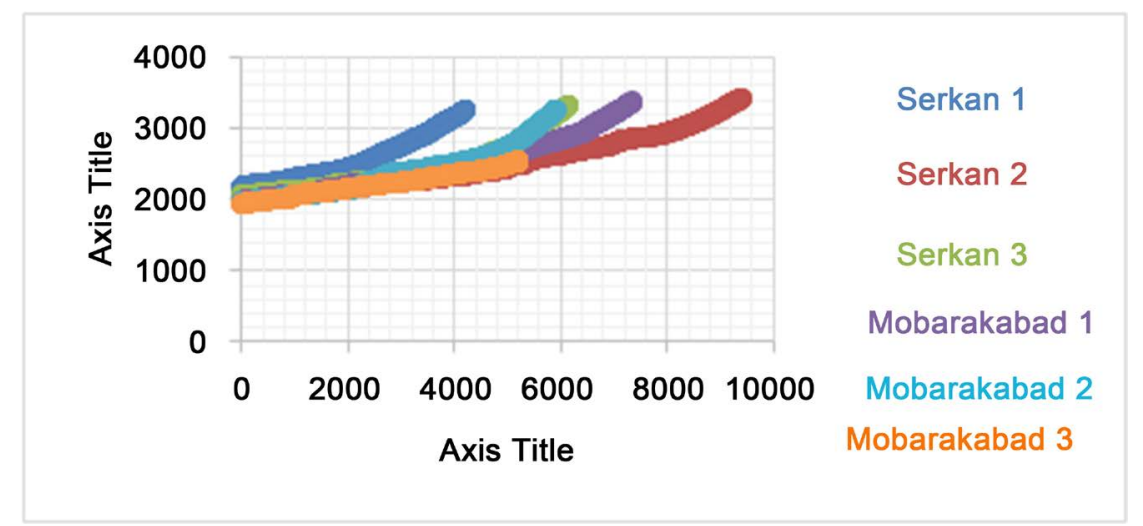

Figure 16. Elevation profile of the 6 glacial valleys of Serkan and Mobarakabad. 
located at the last plain in the studied area. The interesting point is that there is a huge amount of the erratic rocks around the road or Mobarakabad village, which in the first place, these rocks seems as the last glacial moraines and in our assumptions part we also assumed two hypotheses for erratic rocks. Our first hypothesis was that these rocks are glacial effects and have been deposited by the glaciers to this place or they have been brought by the glacial deposits. But due to the ELA calculation digits in the Kuhle and Hofer and Luis methods, it turned out that these rocks are much less than the ELA calculation and these cannot be considered as the glacial moraines, but these rocks were transferred to this place by the mega floods from the six glacial valleys, including the Serkan 1, 2 and 3, and the Mobarakabad 1, 2 and 3 valleys. Of course, maybe the past location of these rocks was in the area of the past ELA and those have a glacial source, but those have been transferred by floods (so it can be concluded that these rocks likely have a glacier-flood source). Therefore, the observed effects of Terminals $1,2,4$, and 5 have no glacial origin and the calculated ELA is not correct. But The Wurm ELA period in terminal number 3 and 6 in the Serkan and Mobarakabad respectively can be approximately considered between (2820) meters in Mobarakabad and (3033) meters in Serkan (according to Kuhle method).

Based on others works and the analysis of aerial photographs, Schweitzer presented the permanent current snow line in the form of a map. According to him, the limit of the current permanent snow line in the Zard Kuh and Alborz is 4200 meters above sea level (Schweitzer 1972). According to this map, the permanent attitude of the snow line is currently increasing significantly from the outer slopes of the marginal mountains to the inner heights (it is in the Alborz region about 4200 meters and in Central Iran above 5000 meters). The map indicates that under present conditions, it is not possible to create permanent glaciers, except for a few crests in other parts of the country. According to the Schweitzer map, the permanent snow line is now $4200 \mathrm{~m}$ and according to Ebrahimi calculations, the current snow line is 4400 meters.

\section{Discussion and Conclusion}

\subsection{Research Objectives}

1) Tracking the quaternary fjord centers (glaciated valley) of the region;

2) Identification of the geomorphologic phenomena and heritages of the fourth period of the region;

3) Identification of glacial landforms and determining the permanent snow line of the last glacial age in the studied area.

\subsection{Questions or Research Hypotheses}

1) What is the effect of the relief's direction in the equilibrium line of water, ice and glacier's formation in the studied area?

2) What are the elevation digits for expansion of the terminal quaternary 
glaciers in the region?

3) What is the attitude of the snow line and morphodynamic and morphoclimatic glacial zones of the studied area in the current and quaternary ages?

\subsection{Results Obtained from the Studies}

\subsubsection{Results Obtained from the Study of the Elevation Digital Models}

The digital elevation model produced by the Country Mapping Organization with a spatial resolution of ten meters, which has high quality and accuracy, has been used in the study and also for producing of three-dimensional models and tracing glacial circuses.

\subsubsection{Results from the Investigation and Identification of Glacial Circuses in the Area of Mobarakabad and Serkan Valleys}

The results of this research have shown that along with field surveys, the $3 \mathrm{D}$ models can be considered as a good tool for identifying the glacial circuses.

- Surveys conducted in the area of the Serkan valleys.

- Surveys conducted in the area of the Mobarakabad valleys.

\subsubsection{The Results of Glacial Geomorphology Studies in Selected Sites}

In this research, we could reconstruct the ancient permanent snow line (Kuhle, Hofer, and Luis... methods) based on comprehensive morphometric studies, field operations, office surveys, and also the use of various methods of the permanent snowline reconstruction. Comparison of the values of the permanent snowline reconstruction has shown that in most study areas, different glacial periods have been active from the Wurm to the new glacial period.

\subsection{Answers to Questions of Research Objectives}

\section{1) Tracking the quaternary fjord centers (glaciated valley) of the region}

During field operations, along with the supervisor professor, the northern and southern slopes of Alvand and a number of their valleys were examined, and the valleys of Serkan and Mobarakabad had more geomorphologic evidences, such as the glacial circus, sidebar moraines, terminal moraines and erratic rocks etc. Therefore, tracking of the Quaternary fjord centers (glaciated valley) of Mobarakabad and Serkan valleys was selected as the subject of this thesis and at the later stages, in the software environment, it was traced the geomorphologic evidences through the satellite imagery and digital elevation models with a precision of 10 meters and a dozen information layers were prepared in this regard.

2) Identification of the geomorphologic phenomena related to the fourth period of the region

In order to identify glacial geomorphologic evidences, and other geomorphologic evidences of the fourth period, a number of evidences were identified during the field operation, including glacial circuses, glacial valleys, sidebar moraines and terminal moraines in the area of the 6 glacial valleys and then, the geomorphologic maps were provided based on Google Earth images and the op- 
erations of 3D construction and preparing the glacial age-form layers.

3) Determining the permanent snow line of the last glacial age in the studied area

In this research, during the field operations, glacial geomorphic evidences such as circuses, sidebar moraines, terminal moraines were identified during several time intervals based on the methods of Kuhle, Hofer, Louis, and the ancient permanent snow line was prepared.

The ancient permanent snow line of the six glacial watersheds was provided based on Kuhle, Hofer and Luis methods. Only two valleys of Serkan 3 and Mobarakabad 3 had a high degree of accuracy in the ELA loss and their past snow lines. It is worth mentioning that the current snow lines are 4400 meters and 4100 meters in this study (according to the Schweitzer map). The results of the estimation of the snow lines for each of the six valleys are given in Table 4.

\subsection{Answering Questions or Research Hypotheses}

1) What is the amount of the effect of the relief direction over the equilibrium line of the water, ice and the glacier's formation in the study area?

The results of the study indicate that the type of slopes, crests' height, direction of the reliefs and dense of crests can affect the permanent snow line location and the equilibrium line of water, ice, and glacier's formation. However, the response to this hypothesis is easier and more correct by completing and determining the quaternary snow lines located on the northern valleys and slopes of the Alvand Kuh and certainly the northern slopes and the direction of its reliefs will show the attitude of the snow line in comparison of the southern slops

2) What are the elevation digits for expansion of the terminal quaternary glaciers in the region?

According to carried out calculations on the Kuhle method, only the existence of the glacial tongue and the terminal moraines have been confirmed in the Serkan 3 and Mobarakabad 3 valleys and according to the Kuhle method, their elevation digits have been reached by 3033 in the Sarkan (3) valley and $2820 \mathrm{~m}$ in the Mobarakabad (3) Valley respectively. Therefore, the past permanent snow line of these two valleys is located at a height of 3033 meters and 2820 meters. Based on the local researches and asking questions in the location, the past floods caused to change the direction of the Mobarakabad River and the Serkan valley in 250 years ago, and the moraines of the Serkan and Mobarakabad valleys have been transported by the mega-floods to the lower elevation digits, namely, from 1700 to 1750 meters. It means that no glaciers reached by 1700 to 1750 meters around the gardens and roads of the Mobarakabad village, and transferring these pseudo-glacial erratic rocks (false moraines) has been carried out by the mega-floods in the past.

3) What is the attitude of the snow line and morphodynamic and morphoclimatic glacial zones of the studied area in the current and quaternary ages?

Now, in the studied area, according the performed study and the Schweitzer 
snow line map, the current permanent snow line is 4100 and 4400 meters, respectively. And in the terminal quaternary, namely, according to performed calculations based on the Kuhle, Hofer and Luis methods, the snow line of the six glacial valleys in the terminal quaternary (late Wurm) is at Table 4.

\subsection{Suggestions}

In order to complete this research, the following suggestions are recommended for future research:

1) The identified glacial moraines in the Serkan 3 and Mobarakabad 3 valleys be carefully evaluated for age.

2) The proposed method be tested for identifying glacial circuses and estimating the ancient ELAs of other valleys of Alvand, especially the northern slopes.

3) It is suggested that Alvand glacial circuses and the valleys studied should be investigated in order the morphometric indices.

\section{Acknowledgements}

I appreciate my dear professor, Dr. Abdullah Seif who associated greatly for performing and accomplishing my scientific research. Here, I also appreciate my dear Dr. Babak Ebrahimi for his useful guidelines and suggestions during the research and performing my dissertation and again, I appreciate the aforementioned professors for their honest servants to realize the scientific and professional affairs in the direction of the Islamic Revolution and the Islamic Republic of Iran.

Hoping for the increasing God mercy.

\section{References}

[1] Pedrami, M. (1982) The Pleistocene Glaciers in Quaternary and the Past Climate in Iran.

[2] Ghohroudi and Hosseini (2012) The Evolution of Glacial Landforms in Border Lines in Iraq and Iran, Geology Conference, November, Kurdistan, 14-16, Sulaimaniyah, Iraqi Kurdistan Region.

[3] Seif, A. (2014) Detection and Study of the Terminal Quaternary Glacial Landforms in Iran's Zagros Heights. PhD Dissertation, Isfahan University, Isfahan.

[4] Seif, A. (2011) Detection of Glacial Morphological Effects of Lorestan in Quaternary. Isfahan University, Isfahan.

[5] Seif, A. (2012) Identification and Investigation of the Glacial Domains of the Middle Zagros in the Terminal Quaternary. Master's Thesis, Isfahan University, Faculty of Geography and Planning, Isfahan.

[6] Ghohroudi (2011) Estimation and Comparison of Snow Line Limit in Glacial and Interglacial Periods of the Basin Cover in the Haraz River, Geomorphology and Progress. 110. (In Farsi)

[7] Yamani (2006) Geomorphology of Zard Kuh Glaciers (Study of Geomorphologic Forms and Their Extensions). Geographical Research, No. 59, 125-139. 
[8] Pleistocene Glaciers in Kurdistan, Azayof, Alter and Jojan Wart 131-164, 12, Google Earth Site.

[9] Servati, M.R. (1990) Quaternary Glaciation in the Inner Parts of the Zardkouh Mountainous in the Zagros Kuh. Geographical Research Magazine No. 26, Department of Geography, Shahid Beheshti University, Tehran.

[10] Ghohroudi et al. (2013) Geomorphologic Evidences and Sediment from Alpine Glaciers in the Zagros Mountains of Iran. Payame Noor University, Sulaymaniyah.

[11] Comprehensive Studies Center of Hamedan Province Development (2000) Comprehensive Development of Tuyeserkan City.

[12] Sahab Geography Institute and Cartography (1991) Glaciers and Last Glaciations. Journal of Geography, 17, 545-568.

[13] Digital Elevation Model (DEM) Altitude Digital Model from Aster Satellite Imagery with a Resolution of 10 Meters.

[14] Kuhle, M. (1976) Beitrage Zur Qartarmorphologie SE- IraniScher Hochgebirge Die Qartare vergletscherung des kuh-i-jupar. Gottinger Geographische Abhandlungen: No. 67. 2 Volume, 103, 209.

[15] Ebrahimi, Babak, (2016) Tracing and Studying the Late Quaternary Glacial Landforms in Iran's Zagros Heights. Doctoral Dissertation, Isfahan University, Professor Dr. Abdollah Saif. 